\title{
Study of Plant Pathogen Interaction in Groundnut Challenged with Sclerotium rolfsii by Scanning Electron Microscopy
}

\author{
S. Rajasekhar ${ }^{1 *}$, Y. Amaravathi ${ }^{2}$, R.P. Vijayalakshmi ${ }^{3}$, \\ R.P. Vasanthi ${ }^{4}$ and N.P. Eswara Reddy ${ }^{2}$
}

${ }^{1}$ Acharya N.G. Ranga Agricultural University, Department of Molecular Biology and

Biotechnology, S.V. Agricultural College, Tirupati-517502, India

${ }^{2}$ Department of Molecular Biology and Biotechnology, ${ }^{4}$ Department of Genetics and Plant

Breeding, IFT, RARS, Tirupati-517502, India

${ }^{3}$ Department of Physics, S.V. University, Tirupati-517501, India

*Corresponding author

\begin{abstract}
A B S T R A C T
The present investigation was aimed to understand early infection process and plant pathogen interactions involved in tolerance and susceptibility in groundnut challenged with Sclerotium rolfsii by Scanning Electron Microscopy (SEM). The histo-pathological changes were recorded

Keywords

Groundnut, Sclerotium rolfsii, Mycelium, Scanning electron microscopy

\section{Article Info}

Accepted:

10 April 2019

Available Online:

10 May 2019

at different time intervals in two groundnut genotypes with differential reaction to stem rot disease viz., Cv: "ICGV 86590" (resistant) and Cv: "Narayani" (susceptible). These genotypes were grown in glass house and challenged with stem rot pathogen. The infection process and host-pathogen interactions were examined at cellular level in both resistant and susceptible cultivars at 24, 48 and 72 hours after inoculation (HAI). The SEM observation showed the direct penetration of fungal hyphae through the cuticle was observed within 24 HAI of inoculation in Narayani whereas no sign of mycelial growth was found in resistant genotype ICGV 86590. In the $S$. rolfsii challenged tissues, fungal hyphae were developed in both inter and intra-cellular layers within $48 \mathrm{HAI}$ in Narayani and completely colonization with fungal mycelium was observed within 72 HAI and thereby lead to tissue collapse in susceptible genotype. In contrast, the resistant genotype has no mycelial growth in xylem vessels even at 72 HAI. In Cv. Narayani, after invasion of the fungus, rapid degradation of cell wall occurred in the stem followed by intercellular and intracellular spread of the fungal mycelium was observed. Finally, tissues of the stem lost their integrity and seemed as rotten mass covering with dense mycelium. The SEM study in groundnut clearly demonstrated the difference in histo-pathological responses in resistant and susceptible cultivars while the infection process of S. rolfsii.
\end{abstract}

\section{Introduction}

Stem and pod rot is one of the major constraints in groundnut production as it severely affect the yield and quality of the produce (Mehan and McDonald, 1990). In India, it occurs in all groundnut growing states and most severe in Andhra Pradesh, Maharashtra, Gujarat, Madhya Pradesh, Karnataka, Orissa and Tamil Nadu (Kumar et 
al., 2013). Yield losses range from 10 to $25 \%$ annually. The disease incidence will be more severe reach upto $80 \%$ during stem rot epidemics coincides with wet climatic conditions prevailed at pod filling (Akgul et al., 2011).

Stem rot is caused by Sclerotium rolfsii Sacc., is a ubiquitous, soil-borne, necrotrophic pathogen with a wide host range of agricultural and horticultural crops belonging to 100 families (Punja et al., 1985). It attacks at any stage of crop growth and affects both above and underground plant parts ranging from roots to shoots whereas stem infection at the collar region is the most common and devastating (Ganesan et al., 2007). The pathogen also attacks pods and diseased pods show characteristics bluishgray discoloration known as "blue damage" (Madhan et al., 2013) and severely reduce the quality of the seeds and recovery of the produce and thereby reduces yield and fetches poor price. Fungal attack in groundnut triggers a variety of host defense mechanisms including production of phytoalexins and antifungal proteins that degrade fungal cell walls or cause other deleterious effects on the invading pathogen (Zinnat and Robert, 2012) which in turn helps in restraining the pathogen from establishment and further multiplication and thereby results in resistance. In a susceptible disease reaction, once the pathogen comes in contact with the groundnut plant surface, the spores germinates and hyphae spreads both intra and inter cellular growth results in a sponging interaction between the host and the pathogen (David and Brown, 1997). S. rolfsii can penetrate into the non-wounded host seedlings directly by the formation of appressoria. It may also gain entry through natural openings such as lenticels and stomata and the disease progresses in both the directions from the sponging point. Smith et al., (1986) reported that the hyphae from germinating sclerotia ramify over various host tissues within 24-48 hrs following inoculation. The persistence of the pathogen in the soil and wide range of hosts often limits the effectiveness of management of the stem rot disease (Buensanteai et al., 2012). Development of resistant cultivars could be an effective and economical management strategy especially for soil-borne polyphagous pathogens like $S$. rolfsii. Resistance breeding in groundnut for stem rot disease management requires a better understanding of the plant pathogen interactions (Ma et al., 2009) and key facors resulted in resistance reaction. Presently, research on plant pathogen interaction studies of stem rot pathogen and groundnut genotypes are scanty. The present investigation was undertaken to understand the host-pathogen interaction (sclerotium rolfsii \& groundnut cultivars) during infection processes and thereby formulate effective disease management strategies.

\section{Materials and Methods}

\section{Source of plant material}

Two contrasting groundnut genotypes with respect to stem rot viz., Cv: "ICGV 86590" and Cv: "Naraynai" were obtained from RARS, Tirupati, India. Cv: "ICGV 86590" is also a Spanish buch groundnut genotype with medium duration of 120 days with tolerance to biotic stresses like rust, late leaf spot, stem and pod rot where as Cv: "Naraynai" is a Spanish bunch groundnut genotype with short duration (100 days) and good plant architecture but susceptible to most of the biotic stresses including stem rot.

\section{Source of stem rot pathogen}

Pure culture of $S$. rolfsii isolate most prevalent in Tirupati was obtained from Dept. of Plant pathology, IFT, RARS, Tirupati to carry out studies described here. 
Multiplication of Sclerotium rolfsii inoculum

The stem rot fungus was multiplied on potato dextrose agar (PDA) media. One matured sclerotial body from pure culture was aseptically transferred to the center of PDA media and the plates were incubated at $27 \pm 3^{\circ} \mathrm{C}$. Proper mycelial growth was obtained within 5-7 days and mature sclerotial bodies were formed after 15-20 days.

\section{Challenging groundnut plants with Sclerotium rolfsii}

Contrasting genotypes to stem rot viz., Cv: "Narayani" and Cv: "ICGV 86590" were sown in pots under glass house conditions. The 45 days old groundnut plants were challenged with the $2 \mathrm{~cm}$ diameter mycelium disc of $S$. rolfsii along with one germinated sclerotial body near collar region (hereafter mentioned as sample). The congenial conditions for $S$. rolfsii were maintained at challenged portion by placing absorbent cotton at the site of inoculation. Challenged samples were collected at $24 \mathrm{hrs}$ interval up to three days after inoculation and further used for Scanning Electron Microscopy (SEM) studies.

\section{Sample preparation for Scanning Electron Microscopy (SEM)}

Groundnut stem samples at collar region were collected at $24 \mathrm{hrs}$ interval after inoculation up to four days as described by Nandi et al., (2010) with slight modifications and another set of samples after 30 days after inoculation. The samples were sectioned with a thickness of 0.2 to $0.5 \mathrm{~mm}$ with a fine edged razor and dried in hot air oven at $50^{\circ} \mathrm{C}$ for four days. The dried samples were mounted on a SEM aluminum stubs using double-sided adhesive tape and sputter-coated with gold particles. The gold particles were ionized through Ion coater prior to SEM. The mycelial growth was recorded in challenged and respective control samples of groundnut Cv: "Narayani" and Cv: "ICGV 86590". The photographs were taken under a scanning electron microscope (ZEISS-EVO-18 Special edition).

\section{Results and Discussion}

After challenging the groundnut genotypes of both Cv: "Narayani" and Cv: "ICGV 86590" collar region with $S$. rolfsii at 0 HAI (hours after inoculation) showed compactness of xylem vessels with no mycelial network (Figure 1A and 2A). In challenged " $\mathrm{Cv}$ : Narayani" at 24 HAI, the pathogen reached the xylem vessel of the stem and clear mycelial structures were initiated to form in xylem vessels at $48 \mathrm{HAI}$ (Fig. 1B \& C) and in contrast no signs of mycelial growth was found in resistant genotype viz., "Cv: ICGV 86590" (Fig. 2B \& C).

Plants possess inducible defense system to withstand the attack of the pathogens. A susceptible disease reaction requires the establishment of a parasitic relationship between the pathogen and the host, once the pathogen has gained entry to the plant (David and Brown, 1997). S. rolfsii penetrates into the non-wounded host seedlings directly by the formation of appressoria. It may also gain entry through natural openings such as lenticels and stomata. Smith et al., (1986) reported that the hyphae from germinating sclerotia ramify over various host tissues within 24-48 hrs following the inoculation.

Early recognition of the pathogen and activation of resistance responses is often responsible for determining the compatibility or incompatibility of host-pathogen interaction. S. rolfsii in groundnut is a necrotrophic pathogen showing typical symptoms of vascular wilt pathogens by the growth of mycelium in the xylem vessels and 
interfere with translocation of water which in turn leads to wilting of the affected branches (Yadeta and Thomma, 2013).

As the infection progressed, the hyphae of $S$. rolfsii were developed rapidly by inter and intra-cellular colonization of xylem vessels in the stem tissues of Cv: "Narayani'. Host cells were disorganized and eventually collapsed. The growth of mycelium in the xylem vessel was more prominent at $72 \mathrm{HAI}$ in $\mathrm{Cv}$ : "Narayani” (Fig. 1D).

As xylem vessels were occupied by mycelium in Cv: "Narayani" which hampers solute transport causing wilting in susceptible genotype. In Cv: "ICGV 86590" (resistant genotype) even at $72 \mathrm{HAI}$ also no hyphae were observed in xylem vessels and the stem sections were very clear (Fig. 2D). This genotype effectively curtailed the pathogen entry in initial stages itself.

The hyphal growth in "Cv: Narayani" at 30 days after challenging with $S$. rolfsii displayed complete distorted xylem vessels occupied by fungal hyphae and complete rotting and death of the stem at collar region when compared to 0 HAI (Figure 3A \& B). In resistant genotype, “Cv: ICGV 86590” samples doesn't show any hyphal growth in xylem vessels even after 30 days after challenging with $S$. rolfsii (Figure $4 \mathrm{~A} \& \mathrm{~B})$. This clearly showed that the genotype "Cv: ICGV 86590" effectively controlled the entry of the pathogen in the initial stages itself and there by resulted in resistant reaction to stem rot.

Garg et al., (2010) reported hypersensitive response associated with resistant genotype against Sclerotium sclerotiorum in Brassica napus whereas hyphae continued to grow in intercellular and intracellular spaces in susceptible genotype. Similar kind of growth response was found in Ascochyta rabiei which produce appressoria that penetrated both cuticle and stomata in chickpea 3 DAI (Ilarslan and Dolar, 2002). Sunflower challenged with Sclerotinia sclerotiorum, the susceptible host cells are completely colonized by mycelium within 48 hours (Davar et al., 2012) which in turn led to tissue collapse. Nandi et al., (2013) also reported mycelial growth of $S$. rolfsii in cowpea xylem vessels at 3 DAI.

Compact xylem vessels with no mycelium hyphae were observed in "Cv: ICGV 86590" even after 72 HAI. Similarly histopathological differences between cucumber cultivars with differential reaction to fusarium wilt showed slower growth of hypha in the vessels of the resistant cultivar when compared to that of susceptible cultivar and hyphae were not observed in the parenchyma cell spaces of the resistant cultivar (Chen et al., 2003).

Sujit kumar (2015) reported the formation of tyloses as a resistance mechanism in groundnut genotype CS19 against $S$. rolfsii at 5 DAI whereas no such cellular responses were seen in susceptible genotype. This kind of structures was not noticed in $\mathrm{Cv}$ : "ICGV 86590 " tolerant genotype.

The tolerant genotypes halt or restrain the pathogen entry as the initial response and further spread in the xylem vessels will be restricted by the formation of tyloses (Sujit kumar, 2015). In addition to this, chemical defense responses which include biochemical components like cell wall degrading enzymes, production and accumulation of pathogensis related (PR) proteins also prevents invasion of the pathogen and inhibit its growth.

The present study has detailed the infection processes and pathogen development was both inter and intra cellular in the susceptible host plant ("Cv: Narayani”) when compared to resistant genotype. 
Fig.1 Scanning electron photomicrographs of Cv: "Narayani" healthy and infected stem tissues stem anatomy showing features of cellular responses at 24 hrs interval up to three days after inoculation (A-D). A. Healthy stem tissue showing the compactness of xylem vessels with no traces of S. rolfsii mycelium. B, C. Infected stem anatomy showing distorted xylem vessel at 24, 48 HAI. D. A closer view of xylem tissue occupied by $S$. rolfsii hyphae (white arrow) at 72 HAI
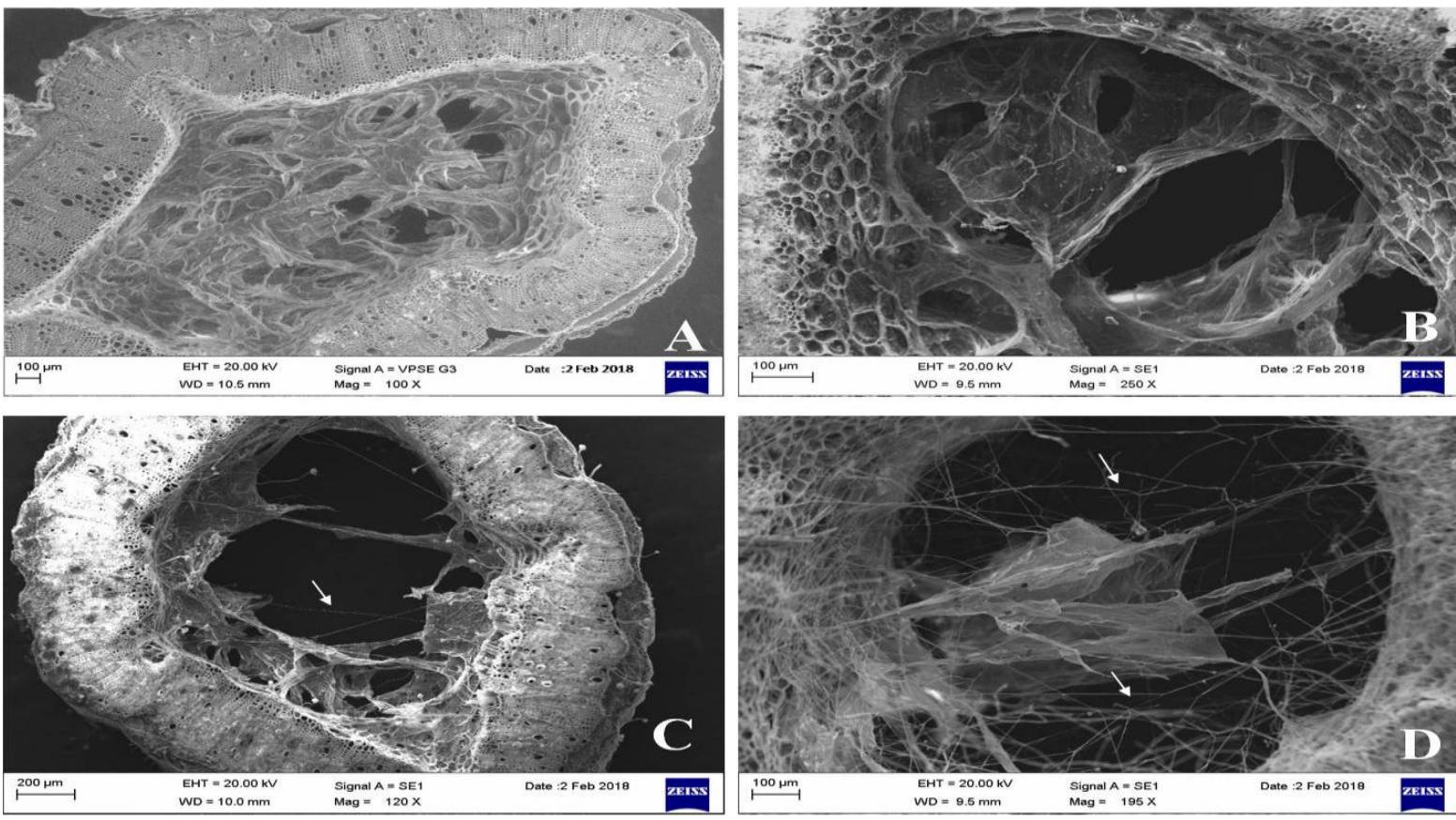

Fig.2 Scanning electron photomicrographs of Cv: "ICGV 86590" healthy and infected stem anatomy showing features of cellular responses at $24 \mathrm{hrs}$ interval up to three days after inoculation (A-D). (A). Healthy stem anatomy showing the compactness of xylem vessels at 0

HAI. Infected stem anatomy showing the compactness of xylem vessels at 24, 48, 72 HAI without hyphal growth (B), (C), (D)
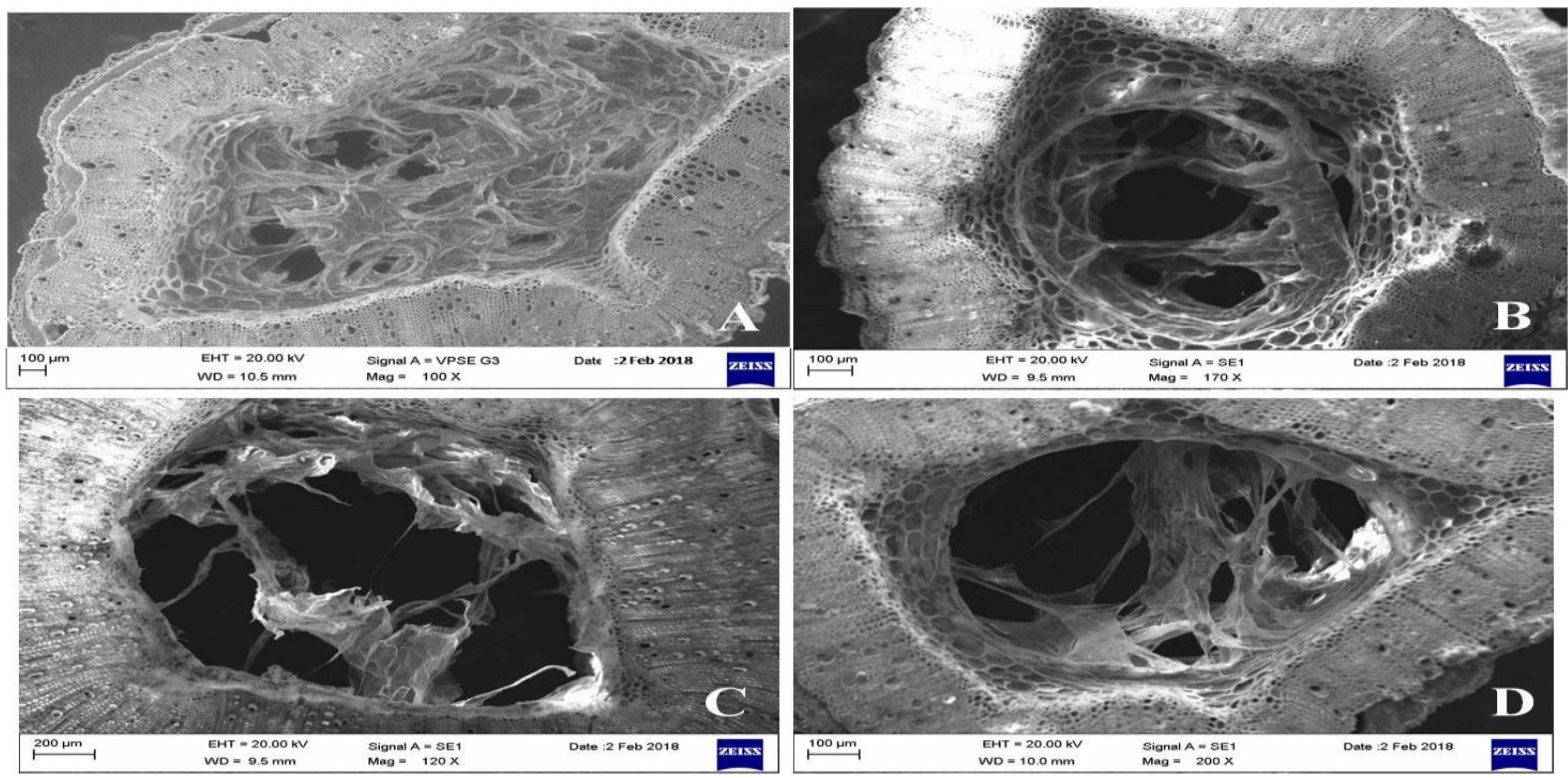
Fig.3 Scanning electron photomicrographs of Cv: "Narayani" healthy and infected stem tissues with Sclerotium rolfsii at 0 HAI and 30 days after inoculation. (A). Healthy stem tissue showing no traces of mycelial growth with compact xylem vessels. (B). Infected stem anatomy showing distorted and collapsed xylem vessel at 30 days after inoculation
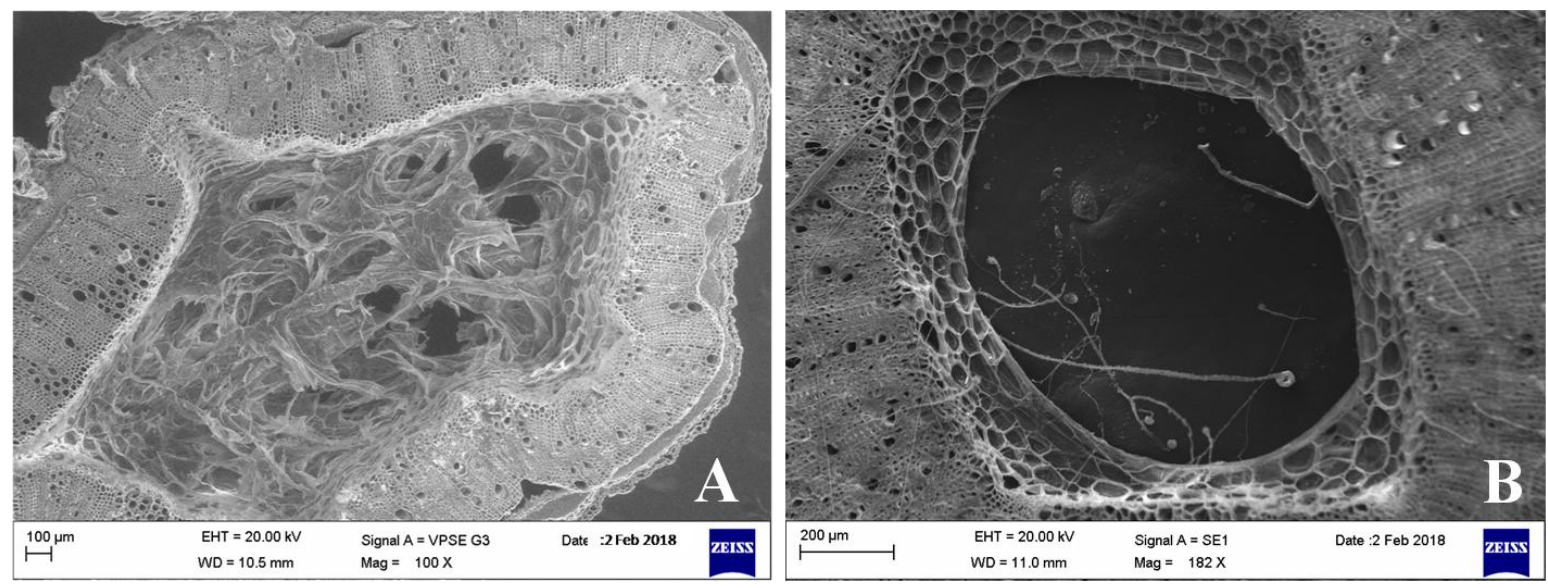

Fig.4 Scanning electron photomicrographs of healthy and infected stem tissues of Cv: "ICGV 86590 " at 0 hrs and 30 days after inoculation. (A). Healthy stem anatomy showing the compactness of xylem vessels with no mycelial growth at 0 HAI. (B) Infected stem anatomy without mycelial growth even at $30 \mathrm{DAI}$ (days after inoculation)

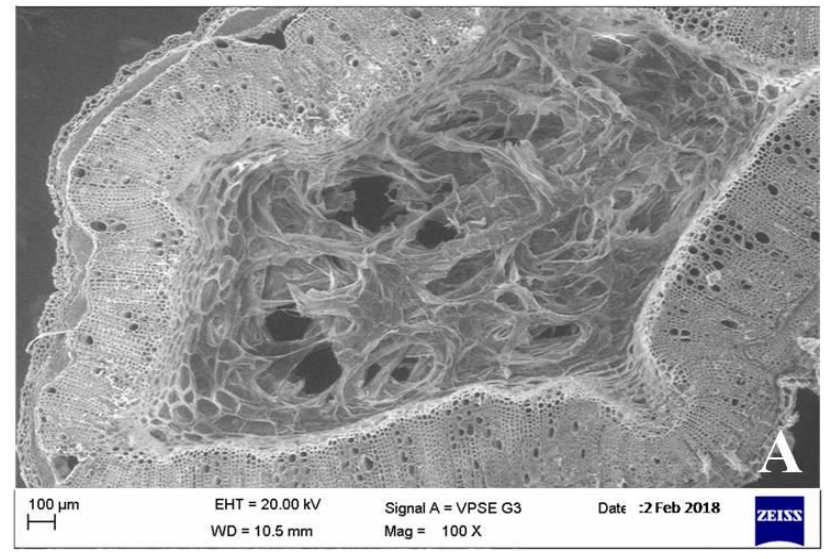

Also our studies have depicted the presence of distorted xylem vessels occupied by the fungal hyphae which hampers solute transport causing wilting in susceptible genotype after 72 HAI whereas resistant genotype ("Cv: ICGV 86590" ) did not show any traces of mycelial growth. Overall, our studies have demonstrated the difference in histopathological responses both in resistant and susceptible cultivars during infection process to stem rot.

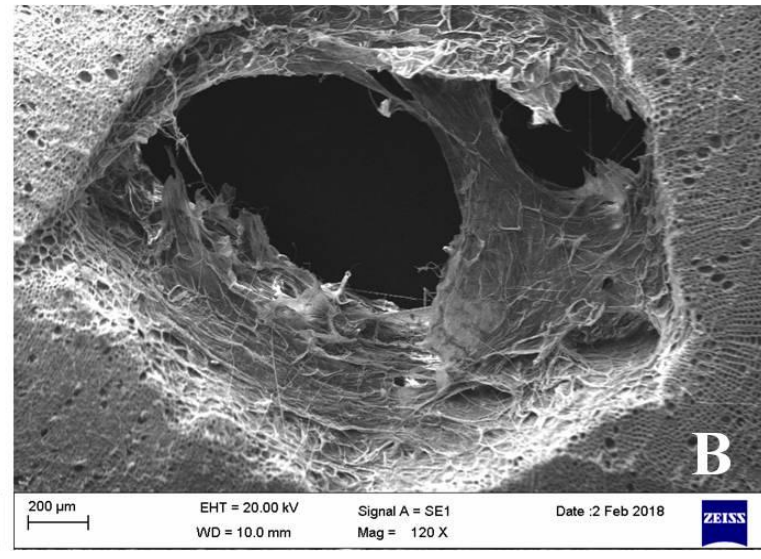

\section{Acknowledgements}

The cooperation from Department of Physics, S. V. University, Tirupati, in preparation of samples and electron microscopy examination is appreciatively acknowledged. The help provided by Department of Molecular Biology and Biotechnology, IFT, RARS, Tirupati, for providing conditions pot culture experiments in glass house and Department of 
Pathology, for supplying pure culture of pathogen is greatly appreciated.

\section{References}

Akgul, D.S., Ozgonen, $\mathrm{H}$ and Erkilic, A. 2011. The effects of seed treatments with fungicides on stem rot caused by Sclerotium rolfsii Sacc in peanut. Pakistan Journal of Botany. 43 (6): 2991-2996.

Buensanteai, N., Thumanu, K., Kooboran, K., Athinuwat, D and Sutruedee P. 2012. Biochemical adaptation of phytopathogenic fungi Sclerotium rolfsii in response to temperature stress. African Journal of Biotechnology. 11 (84): 15082-15090.

Chen, M., Wang, G., Dingtlua, W.U and Cheng, Y. 2003. Histopathological differences between cucumber cultivars with different resistances to Fusarium wilt. Journal of South China Agriculture University. 24 (4): 110112.

Davar, R., Darvishzadeh, R., Majd, A., Masouleh, A.K and Ghosta, Y. 2012. The infection processes of Sclerotinia sclerotiorum in basal stem tissue of a susceptible genotype of Helianthus annuus L. Notulae Botanicae Horti Agrobotanici. 40: 143-149.

David, G and Brown, J. 1997. Plant pathogens and plant diseases. Rockvale publications national library of Australia ISBN. 1-86389-439: 263-260.

Ganesan, S., Kuppusamy, R and Sekar, R. 2007. Integrated management of stem rot disease (Sclerotium rolfsii) of groundnut (Arachis hypogaea L.) using Rhizobium and Trichoderma harzianum. Turkish Journal of Agriculture and Forestry. 31: 103-108.

Garg, H., Li, H., Sivasithamparam, K., Kuo, J and Barbet, M.J. 2010. The infection processes of Sclerotinia sclerotiorum in cotyledon tissue of a resistant and a susceptible genotype of Brassica napus. Annals of Botany. 183: 1-12.

Ilarslan, F and Dolar, S.H. 2002. Histological and ultrastructural changes in leaves and stems of resistant and susceptible chickpea cultivars to Ascochyta rabiei. Journal of Phytopathology. 150 (6): 340-348.

Kumar, N., Dagla, M.C., Ajay, B.C., Jadon, K.S and Thirumalaisamy, P.P. 2013. Stem Rot: A Threat to Groundnut Production. Popular Kheti. 1 (3): 26-30.

Ma, J., Huang, X., Wang, X., Chen, X., Qu, Z., Huang, L and Kang, Z. 2009. Identification of expressed genes during compatible interaction between stripe rust (Puccinia striiformis) and wheat using a cDNA Library. BMC Genomics.10: 586-597.

Madhan, M.M and Nigam, S. 2013. Principles and Practices for Groundnut Seed Production in India. Information Bulletin No. 94. Patancheru, Andhra Pradesh, India: International Crops Research Institute for the Semi-Arid Tropics. pp 36.

Mehan, V.K and McDonald, D. 1990. Some Important diseases of groundnut sources of resistance and their utilization in crop improvement. Paper presented at the In Country Training Course on Legumes Production. Pp. 9-17.

Nandi, S., Dutta1, S., Mondal1, A., Adhikari1, A., Nath, R., Chattopadhaya, A and Chaudhuri, S. 2013. Biochemical responses during the pathogenesis of Sclerotium rolfsii on cowpea. African Journal of Biotechnology. 12(25): 39683977.

Punja, Z.K. 1985. The biology, ecology and control of Sclerotium rolfsii. Annual Reviews of Phytopathology. 23: 97-127.

Smith, V.L., Punja, Z.K and Jenkins, S.F. 1986. A histological study of infection of host tissue by Sclerotium rolfsii. 
Phytopathology. 76: 755-759.

Sujit Kumar, B. 2015. Biochemical and Molecular basis of innate and Pseudomonas fluorescens induced stem rot tolerance in groundnut (Arachis hypogaea L.). M.Sc. (Biochemistry) thesis, Junagadh Agricultural University, Junagadh, India.
Yadeta, K.A and Thomma, B.P.H.J. 2013.The xylem as battleground for plant hosts and vascular wilt pathogens. Frontiers in Plant Science. 23(4): 97.

Zinnat K and Robert L.W. 2012. Scanning Electron Microscopy of the invasion process of Phytophthora infestans on potato leaves. IRJALS. 1(2): $20-26$.

\section{How to cite this article:}

Rajasekhar, S., Y. Amaravathi, R.P. Vijayalakshmi, R.P. Vasanthi and Eswara Reddy, N.P. 2019. Study of Plant Pathogen Interaction in Groundnut Challenged with Sclerotium rolfsii by Scanning Electron Microscopy. Int.J.Curr.Microbiol.App.Sci. 8(05): 1031-1038. doi: https://doi.org/10.20546/ijcmas.2019.805.121 